\title{
Fac-símile do texto A Educação Brasileira ${ }^{1}$
}

\author{
Facsimile of the text A Educação Brasileira
}

Introdução do Editor

Nesta edição da O que nos faz pensar dedicada ao ensino de filosofia, aproveitamos para publicar, como um documento que dá testemunho histórico a respeito da educação, um texto de 1988 de Therezinha Gonzaga Ferreira Lessa. Therezinha formou-se em Pedagogia e fez Mestrado em Educação na UFRJ. No entanto, a sua trajetória foi marcada sobretudo pela relação com o CEAT - Centro Educacional Anísio Teixeira. Fundado em 1969, ainda como filial da Escola Pueri Domus de São Paulo, o colégio ganhou identidade muito específica a partir de 1984, ano de instauração do Ensino Médio e no qual, com a orientação de Therezinha, tornou-se uma sociedade sem fins lucrativos gerida por seus funcionários.

No texto aqui publicado, Therezinha discute a educação no Brasil, tendo em vista o contexto social, histórico e político do país. Se, por um lado, o texto é datado, na medida em que lida com os problemas de sua própria época, por outro lado também pode ajudar a perceber as permanências que certas discussões têm quando pensamos a educação no Brasil - e os entraves que se colocam para o seu avanço ontem e ainda hoje. Fica aqui o agradecimento à família de Therezinha, em especial à sua filha Bia Lessa, que nos cedeu o original aqui publicado.

Pedro Duarte EDITOR

1 Publicação póstuma.

* Centro Educacional Anísio Teixeira 
Ao Conselho Editorial

da Revista Recursos Humanos e Sociedade

Tendo sido colaboradora da Revista de Cultura Vozes, tivemos publicado um artigo denominado "O descaso pela pedagogia" (revista no. 2, pg. 115) e uma resenha do livro "Métodos de Estudos para o 2 \% grau", de autoria de Antonio Joaquim Severiano. Temos em mãos a revista Recursos Humanos e Sociedade, da mesma editora.

Despertou a nossa atenção o I Encontro de Profissionais de Informática e Recursos Humanos e decidimos elaborar um artigo sobre "Educação Brasileira", questionando a introdução da informātica, da tecnologia educacional na educação dentro do contexto da história, da legislação e das inovações propostas no período de 1930 atē hoje.

Anexamos nosso currículo e adiantamos que de 1974 a 1984, fomos diretora do Centro Educacional Anísio Teixeira, o CEAT, e que a partir de 1985, assumimos o cargo de Consultora Pedagógica. Em sua verticalidade o CEAT abrange de creche ao 28 grau.

Trabalhamos durante dez anos objetivando criar condições pạ ra que nossos alunos, professores e o pessoal da administração adquirissem conhecimentos que os capacitassem a criticar a realidade social e física, e a agirem como agentes de mudança social.

Para sermos coerentes com a busca da justiça social, com a humanização do desenvolvimento brasileiro, abrimos mão da propriedade privada formada por Mary Miranda Alvarenga, Mary Cortes Fernandes e esta que assina a carta e o artigo "Educação Brasileira", em favor dos funcionārios que se dispuseram a assumir os direitos e as responsabilidades de se associarem numa sociedade por cotas, uma Entidade sem fins. lucrativos.

Temos consciência de que como inovação pedagógica com referência ao nosîo país, essa decisão,não tem o menor significado, pois, só atinge mil e duzentos alunos e cento e vinte funcionários. 
Temos consciência também de que teoricamente è um equívoco efetivar a transformação de uma escola de capital privado numa escola * de capital dividido por cotas entre todos os funcionários. Uma escola socialista, portanto, dentro de um contexto capitalista. Mas não o fizemos equivocamente, mas intencionalmente porque consideramos que para transformar é preciso ousar. E transformamos o que estava em nosso alcance, fazer.

Rio, de março de 1988

Therezinha Gonzaga Ferreira

Consultora Pedagógica do Centro

Educacional Anísio Teixeira.

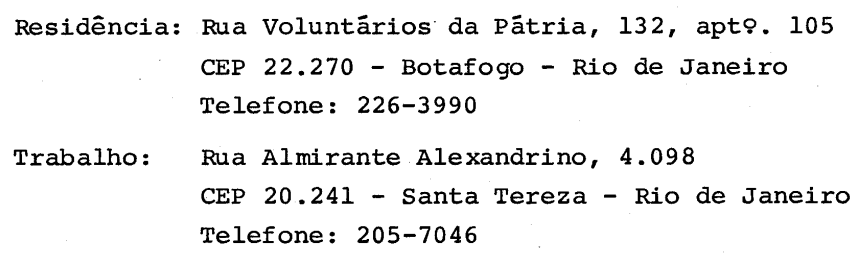




\section{A EDUCAÇÃO BRASILEIRA}

A História da Educação Brasileira é dolorosa para nós educa dores, no sentido de que desde o seu início vem servindo aos poderosos, à elite dominante e mantendo até hoje, 1988 as mesmas mazelas que se perpetuam desde a sua origem.

Para comprovar essa assertiva, duas notícias publicadas pelo Jornal do Brasil do Rio de Janeiro, datadas de 13.12.87.

"Cada estudante universitário das escolas públicas custa cerca de duzentos mil cruzados anuais. Este dinheiro beneficia estudantes de alto poder aquisitivo."

"O Brasil tem hoje dois milhões e quatrocentas mil crianças, fora da escola."

Como variāveis que causam esse fenômeno, podemos citar a ideologia liberal decorrente do capitalismo dependente no qual o Brasil está inserido. A repetência e a reprovação dos alunos das esco: las públicas na primeira série, como tambēm a evasão escolar pela necessidade da criança da classe popular precisar trabalhar para ajudar no sustento da família e também pela inadequação do processo de ensino-aprendizagem às caracterísiticas do aluno da classe considerada subalterna.

Vamos tratar da historicidade da educação brasileira a partir de 1930, contextualizada na perspectiva econômica, política e so$\operatorname{cial}^{1}$.

Em 1918 estava no governo Whashington Luiz, representando o Partido Republicano Paulista.

O modelo econômico até então vigente era o agro-exportador, centrado na cafeicultura em transição para o industrial.

A referida transição do modelo econômico gerou crises políticas intensas nesse período, como a greve geral ocorrida em 1917 ,que obrigou Washington Luiz, a deixar a cidade de s. Paulo.

\footnotetext{
${ }^{1}$ RIBEIRO, Maria Luiza Santos. História da Educação Bràsileira: a organização escolar. S.P., Cortez e Moraes, 2a. ed., rev., 1979 .
} 
Em 1920 houve um aumento sensível da classe média, composta por funcionārios públicos , comerciantes, profissionais liberais, intelectuais e os militares.

Insatisfeita com a política econômica que não estimulava o processo de industrialização, ainda incipiente, a classe média pressionava o governo com greves e em 1920 houve a Revolta do Forte de Copacabana e em 1922 o movimento "tenentista" liderado por Luiz Carlos Prestes.

Em 1922, refletindo os conflitos dessa conjuntura histórica, a Semana de Arte Moderna faz a sua "revolução" nas artes, transforman do inteiramente o que vinha sendo produzido como transplante cultural e expressando a arte brasileira. Destacamos Oswald de Andrade na literatura; Tarsila do Amaral, e Mario de Andrade.

Quanto à educação houve algumas propostas levadas a efeito por Anísio Teixeira na Bahia; por Carneiro Leão, em Pernambuco, por Fernando de Azevedo no Distrito Federal, por Francisco Campos em Minas e a de Lourenço Filho, no Ceará.

A proposta de renovação do ensino que mais se destacou foi a de Anísio Teixeira, proposta essa que foi utilizada contemporâneamente pelo vice-governador do Rio de Janeiro, Darcy Ribeiro, na construção dos CIEPS (Centros Integrados de Ensino Público).

No entanto, apesar desses educadores haverem denunciado a insuficiência do atendimento escolar e os altos indices de analfabetismo, essas reformas não passaram de transplantes culturais, cujas bases teóricas e metodológicas foram elaboradas por John Dewey e que pecavam pela generalidade, abstração e pedagogismo, isto é, sem estabelecer relação entre a educação e o contexto econômico-político-social em que a mesma se insere.

- Cumpre observar que os CIEPS não padecem desse equívoco; considerar a educação autônoma, neutra em relação à totalidade social da qual faz parte.

A cisão da oligarquia do café, permitiu que a revolução de

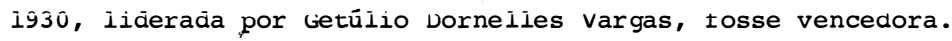


De acordo com Luiz Pereira, l a fase posterior à revolução de 30, significou o grande despertar da sociedade brasileira para as causas de seu subdesenvolvimento. Duas causas deveriam ser atacadas: - reconhecimento de que uma economia agro-exportadora não oferecia condições de desenvolvimento e de que a dependência da economia brasileira em relação à economia externa, deveria ser rompida.

Tem origem, então, a ideologia nacional desenvolvimentista e o modelo econômico, substituição de importação.

A educação continua sendo processo de transplante cultural e de uma concepção ingênua da realidade.

Apoiado pela classe média, pelas classes populares, pelos Estados Unidos que desejavam substituir os ingleses na exploração de nossas riquezas, Getülio Vargas no início de seu governo, não tendo defińido um programa de ação, não tinha liderança suficiente para man ter unidos segmentos sociais tão heterogêneos, que se aglutinaram for mando a "Aliança Liberal". Esta se fragmenta em 1931.

Os protestos e descontentamentos começaram a se expressar atravēs da insatisfação das classes populares, dos intelectuais e dos educadores que em março de 1932 assinaram o "Manifesto dos Pioneiros em Educação", liderado por Fernando de Azevedo e por mais vinte e cin co educadores, entre eles Anísio Teixeira.

Com o referido Manifesto se introduz no Brasil, a Escola Nova que propunha para as classes primārias período integral, para o segundo grau o desenvolvimento da racionalidade científica e para as universidades a formação de profissionais especializados em diferen-i tes campos de conhecimento para atender ã demanda do mercado de traballho. Lutavam pela escola pública.

Defendiam ainda a laicidade, a coeducação, a obrigatoriedade e a gratuidade do ensino, mantido e custeado pelo Estado.

Nesse período ocorreram acirrados debates entre educadores católicos e os das "idéias novas", acusados de serem comunistas.

Os educadores católicos lutavam pela escola particular, pe-

IPEREIRA, Luiz. Capitalismo: notas teōricas. São Paulo: Duas Cidades, 1977. 
lo ensino confessional, contra a coeducação. Justificavam a exigência da não ingerência do Estado na educação, para que as famílias pudessem escolher entre as instituições escolares aquela que . complementasse os valores da educação familiar.

Essas posições tão radicalmente diferenciadas, tinham um ponto de vista comum: os dois grupos eram contra o monopólio do ensino, pelo Estado.

Em relação à eđucação continuou influenciada pelo liberalismo, objetivanđo a formação dos educandos para uma civilização urbano-industrial.

Equivocadamente não diferenciavam a civilização urbano industrial da Europa, dos Estados Unidos e do Brasil. Liberalismo geral, abstrato, desvinculado da realidade concreta brasileira.

No primeiro período do governo de Getúlio, de 1930 a 1936 , foi criado o Ministërio de Educação e Saúde, sob a responsabilidade do Ministro Francisco Campos; é empreendida a reforma do Ensino Superior, foi criada a Faculdade de Educação, Ciências e Letras que não se organizou. Reestrutura o ensino secundário, dividido em duas etapas: a primeira com a duração de cinco anos (curso fundamental); a segunda, de dois anos, visando preparar mão de obra para as futuras especializações profissionais.

o desenvolvimento cada vez mais acelerado das forças econômicas, coloca a política federal, numa intensa crise que culmina em 1937 com a decretação do Estado Novo.

"O terror policial, a repressão, foram instrumentos de imposição de uma "paz interna" sentida como necessária pelos grupos dominantes e também por parte da classe média que vai se colocando pela influência do integralismo"l

- Quanto à educação declara ser a arte, a ciência e o ensino livres à iniçiativa particular e pūblica; mantém a obrigatoriedade do ensino primário, institui o ensino de trabalhos manuais; organiza o

IRIBEIRO, Maria Luiza Santos. Obra jä citada. pg. 2. 
ensino prē-vocacional e profissional que se destinam às classes menos favorecidas; estabelece o regime de cooperação entre a indústria e c estado.

Com essas medidas fica explicitada a orientação políticaeducacional capitalista de preparação de mão de obra para novas funções abertas pelo mercado.

Na segunda guerra mundial (de 1939 a 1945), Getúlio exigir para que o Brasil aderisse aos "Aliados" (Inglaterra, E.E.U.U. e países da Europa) um emprēstimo de 20 milhões de dólares, concessão pari venda de armamento a longo prazo e Volta Redonda - Companhia Siderúrgica Nacional.

Começa nesse período a penetração do capital estrangeiro, especificamente dos Estados Unidos que vai atingir o auge em 1955 e c climax em 1964, como o Golpe Militar de 31 de março.

As campanhas contra o Estado Novo, organizadas por todas as classes sociais, inclusive pelas classes populares, base do governc de Getúlio, levaram-no a conceder anistia ao P.C.B. e ele próprio renuncia em 1945.

Candidatou-se ao governo federal, tendo sido eleito, o general Eurico Gaspar Dutra que governou de 1946 a 1950. Sua candidatura foi lançada pelo P.D.S. O fisiologismo na administração federal, estadual e municipal e a inflação, marcaram o governo do genera] Eurico Gaspar Dutra. Alheio às tramas políticas, preocupado apenas com os comunistas deixou escoar seu mandato num ritmo sonolento.

Quanto à educação, manteve a mesma estrutura, restringindo, no entanto, a gratuidade. Em 1948 foi proposta a L.D.B., pelo Ministro da Educação, Clemente Mariano. Em 1946, criou o SENAC.

Eleito democraticamente em 1.951, Getúlio Vargas decide rei. niciar sua aproximação com as massas. Entrega o Ministērio a Jangr Goulart que se liga aos líderes sindicais, dando início à política dc "peleguismo". Cria a Petrobrás e a C.L.T. que régulamenta os direi. tos dos trabalhadores. 
Criou O INEP em 1938, O Serviço Nacional de Radiofusão Educativa, em 1939; O Senai, em 1942; Capes, em 1951 e Cades, èm 1954.

Um substitutivo do deputado Carlos Lacerda, entravou

L.D.B., causando uma polêmica que girava em torno da luta entre escola pūblica e particular e levantava a questão entre centralização e descentralização em relação à educação.

Teoricamente, essas eram as razões do substitutivo, no entanto, de fato, essas razões eram "pretextos" para impedir a aprovação de uma lei que servisse como instrumento adequado à "democratização" da educação em diferentes graus.

"O elemento democrātico da L.D.B. fixado no Art. 2 proclama a educação como direito e dever de todos. Isto, materializado na rea lidade social, significaria que todos não só podem, mas têm obrigação de estudar. Mas como estudar se faltam escolas, professores, material, sendo impossível para muitos cumprir sua obrigação e reinvidicar seu direito pela sua situação de classe? A lei não considera cer tos fatos. Ela omite uma realidade social em que a desigualdade está profundamente enraizada.

Mas ela não se contenta com a omissão, ela parte do princípio de que a sociedade brasileira se caracteriza, como o Social system de Parsons pela igualdade de chances. Assim o filho do lavrador do Nordeste teria as mesmas chances educacionais que o filho de um diretor de uma empresa paulista! A L.D.B. não procura ser um corretivo de diferenças sociais porque acha que não precisa sê-lo. Assim ela traduz no seu texto a estratégia típica da classe dominante que ao mesmo tempo que institucionaliza a desigualdade social, ao nível da ideologia, postula sua inexistência." I

Pelas criticas apresentadas percebe-se a inspiração liberal da L.D.B.. Mas na época em que foi proposta, ameaçou os conservadores. Visava a descentralização do poder de decisão e foi democrática no sentido da ampla discussão que provocou na sociedade civil. Foi discutida tambēm pelos estudantes, organizados em torno da UNE.

\footnotetext{
${ }^{1}$ FREITAS, Bārbara. Escola, estado e sociedade. 3a ed. rev. S. Paulo. Cortez e Moraes, 1979. pg. 17.
} 
Em 1942, a reforma Capanema que abrangeu o ensino secundário e técnico industrial. O ensino secundārio destinado à preparação das individualidades condutoras das massas. Marcadamente conservadora, fascista, moralista, estabelece a dicotomia: escola para ricos e escolas para pobres.

Em 1954, o suicídio de Getūlio Vargas bem como sua cartatestamento, provocaram uma crise de revolta popular.

As eleições são realizadas em 1955 tendo sido eleitos Juscelino Kubitscheck de Oliveira e Jango Goulart cuja meta era fazer - Brasil progredir "50 (cinquenta) anos em cinco": estradas, energia, transporte e a construção de Brasília.

Tiveram o apoio da burguesia industrial e agrária, do operariado sindicalizado e das forças nacionalistas.

Jango Goulart estava na China, em missão diplomātica e as Forças Armadas planejaram a "Operação Mosquito" que pretendia explodir o avião no qual Jango retornou. Foram impedidas de realizar o referido plano pelo General Lott.

E interessante observar que a cultura de massa, utiliza con teúdos reais e muitas vezes da cultura erudita, simplificando-os e di vulgando-os através da televisão. A novela "Mandala", que está sendo levada na TV Globo, narrou o fato histórico jā referido, a "Operação Mosquito."

Com Juscelino e Jango foi estabelecida uma real liberdade política. Pela primeira vez na história do planejamento estatal, uma equipe especializada elaborou o "Plano de Metas" para o governo federal, que se transformou em instrumento do desenvolvimento brasileiro.

No entanto esse período de desenvolvimento econômico, apesar de haver aumentado as possibilidades de emprego, concentrava os lucros em,setóres internos e externos. Como consequência houve o enriquecimento do país e o empobrecimento das classes populares. Outras críticas feita sobre o governo Juscelino e Jango dizem respeito ao abandono em que deixaram o nordeste, a omissão quanto à reforma agräria e a manutenção da instrução İj, da sumoc, elaboraḑa por Nereu 
Ramos que favorecia às empresas estrangeiras concessões cambiais para exportarem maquinārias industriais depreciadas, como se fossem novas. Nesse período a dependência econômica do Brasil em relação aos Estados Unidos, chegou ao auge. Deram portanto, continuidade à dívida externa iniciada no governo de Getúlio Vargas.

Quanto à educação houve muitas invocações e as escolas públicas se multiplicaram porque os políticos viam essa medida como in $\underline{\underline{s}}$ trumento para manter o prestígio entre as classes populares.

As inovações se expressaram nos Movimentos de Educação Popular, no método de alfabetização de Paulo Freyre, como prática para a liberdade; nos Centros Populares de Cultura liderados pela UnE que objetivavam conscientizar as classes menos favorecidas sobre o papel e a função que exercem na sociedade de classes do sistema capitalista. MEB (Movimentoide Educação de Base) aparece em 1961, ligados à CNBB e ao governo.

Em 1958 foi autorizado o funciomamento das escolas experimentais que foram montadas no sentido de servirem como experiência pilôto, e numa fase posterior essa experiência deveria ser ampliada para as escolas püblicas. Os Gināsios Vocacionais, organizados em S. Paulo capital, em Americana, em Campinas, são exemplos dessa inovação, despida inteiramente do liberalismo e voltada para a realidade concreta do povo brasileiro.

Outra iniciativa de grande relevância para a educação brasileira foi a Universidade de Brasilia, idealizada por Darcy Ribeiro e Anísio Teixeira, inteiramente voltada para a transformação social brasileira.

Todas essas iniciativas foram violentamente interrompidas pelo Golpe Militar de 31 de março de 1964.

"A partir da tomada de poder pelos militares o modelo econômico implantado no governo de Getúlio Vargas, cedeu lugar aos investimentos destinados a produzir bens de consumo sofisticados para o mercado interno e externo." I

\footnotetext{
IFREITAS, Bárbara. Obra jā citada na pg. 17 .
} 
Os processos de aristocratização do consumo e as exportações, são interdependentes e a mediação é assegurada pelo capital estrangeiro, representado pelas grandes empresas multinacionais.

Essa política econômica resultou no "climax" do endividamento externo, iniciado no governo de Getúlio e que chegou ao auge no governo de Juscelino e Jango. Resultou ainda numa concentração de renda inimaginävel.

Com cento e trinta milhões de habitantes, o Brasil de hoje, 1988, tem três milhões de indivíduos que compõem a classe dominante, concentrando e acumalando a renda nacional. Os nossos "marajás". Vinte milhões que compõem a classe média a caminho da proletarização e noventa e sete milhões de trabalhadores ganhando salário mínimo, os autônomos e a pobreza total. Este quadro, assim composto, desumano e bārbaro, está acontecendo no governo José Sarney e Ulysses Guimarães, em processo de "transição democrātica."

E óbvio que receberam dos militares o endividamento externo, mas é óbvio também que nada, à não ser reforçar nossa dependência externa e o empobrecimento cada vez maior das classes populares, vem marcando as decisões tomadas pelo atual governo.

A politica educacional a partir de 64 procurou reestruturar - sistema educacional, usando-a como instrumento para controlar a sociedade civil.

E a legislação expressa esse "uso", na nova Constituição de 1967, no governo de Castelo Branco: continua vigindo a L.D.B. e - ensino particular recebe ajuda técnica e financeira. Aumenta a obrigatoriedade escolar de quatro para oito anos, obrigatoriedade essa que jamais foi cumprida. obrigatoriedade "de direito", . mas não "de fato."

A Lei 5540 elaborada em 1968, pelo ministro da Educação Suplicy Lacerda, declara: "os estudantes devem estudar e os professores ensinar (e não fazer poilitica)."

Essa lei resultou do convênio MEC-USAID composto por cinco 
americanos e por dois educadores brasileiros; essa lei ao contrário da L.D.B. que foi longamente discutida pela sociedade civil, foi elaborada nos bastidores.

- texto de lei reflete a racionalização das estruturas e dos recursos materiais e a "democratização" do ensino. Essa combinação expressa o jargão tecnocrātico dos economistas e o jargão liberal dos simpatizantes da democracia.

Cópia do modelo universitário norte americano, estrutura - ensino em básico e profissional (atualmente foi suprimido o ensino básico); dois níveis de pós-graduação, mestrado e doutorado; professores em tempo integral e dedicação exclusiva; assegura a participação aos estudantes nos grêmios universitários e diretorias estudantis sob o controle da lei 477 que considerava ilegal qualquer atividade política; instituiu o vestibular unificado e classificatório, adotado até 1987 e abolido no corrente ano; sistema de bolsas de estudo para os alunos.

A Lei 5692, de 1971, que regulamenta o ensino da pré-escola ao segundo grau, visava conter o enorme afluxo às universi dades que ocorreu nesse período. Estamos destacando esse objetivo, da 5692, mas a mesma não se restringiu ao objetivo citado. A referida lei "procura corrigir as inadequações do sistema de ensino médio anterior, face a uma nova realidade (antes de mais nada econômica) mas tambēm uma decorrêncịa necessāria, da reformulação do ensi no superior, a fim de ajustar ideológica, estrutural e funcionalmente os três níveis de ensino." 1

o afluxo às universidades decorreu da inflação que impossibilitou a manutenção das pequenas empresas; esse contigente composto pelos pequenos empresários foram tentar a entrada na Universidade. As aspirações educacionais despertadas na população pela ideologia liberal estimulavam os estudantes para a entrada no curso superior.

Essa conjuntura causou uma "crise" nas Universidades, que

1 FREITAS, Bārbara. Obra já citada. Pgs.17 e 24 . 
não tinham vagas para atender a demanda.

O Estado utiliza através da Lei 5692 diversos mecanismos para conter a pressão sobre as Universidades, tais como, a proposta dos cursos profissionalizantes com terminalidade no 28 grau; 0 vestibular foi liberado com o sistema classificatório que admitia o número de candidatos igual ao número de vagas independentemente do nível de conhecimento.

Essa medida impedia a aprovação no curso bāsico pela falta de preparo dos alunos e foi complementada pelo "jubilamento" que permitia a eliminação do aluno reprovado no referido curso.

Assim como a Lei 5554 pretendeu cooptar e controlar o estudante brasileiro, a institucionalização do Mobral pela Lei 5692, pretendeu cooptar e conter o operariado. Utilizando e refuncionalizando o método de alfabetização de Paulo Freyre que visava a educação para a liberdade, usou-o para inculcar na população urbana, na faixa, de 15 a 35 anos, os valores do capitalismo autoritário. O Mobral concretiza a ideologia da educação como investimento que significa "o economicismo" em educação e tambēm a doutrinação ao nível político atravēs da adoção da educação moral e cívica.

Recorreram também, ao Ensino Supletivo para suprir a escolarização regular para adolescentes e adultos que não a tivessem seguido ou concluído na idade própria.

O seu relator, Valmir Chagas, junto ao Ministērio de Educação e Cultura, deduz no seu parecer quatro modalidades de ensino: sis tematização dos cursos de treinamento, institucionalizados do Senai e Senac, visando preparação intensiva de mão de obra especializada; suplência (o Mobral) e suprimento que inclui cursos de reciclagem e aperfeiçoamento em qualquer nível. o ens no supletivo reintroduz a forma dual dé um sistema de ensino que prepara em cursos diferenciados, as classes dirigentes e as classes subalternas.

Completamos com esse quadro a Histōria da Educação Brasileira e perguntamos que alternativas existem para superar problemas

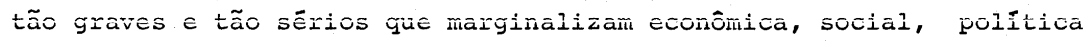


e culturalmente, a grande massa popular, estimada em 97 milhões de pessoas? Que caminhos, ou quais alternativas existem para se superar os problemas da educação brasileira?

Savianil aponta: a descolarização proposta por Ivan Ilitch em "Uma Sociedade sem Escolas," associada aos meios de educação de massa. Outros autores admitem que a escola tem alguma função a exercer, mas consideram seu papel subalterno e transferem o papel principal da atividade educacional para os meios de comunicação de massa. A eles associadas aparecem, ainda, as tecnologias do ensi no, a informātica, a educação via satélite, a educação computadorizada, que poderiam ser introduzidas na escola, como um meio de melhorar a apren dizagem.

A Educação Permanente é outra alternativa que se apresenta e que encampa todas as outras, porque considera o ser humano como um ser sempre inacabado.

Serão essas alternativas "modismos" tão ao gosto de educadores que sem refletir sobre as propostas de inovação, vão adotando-as numa atitude : acrítica e ingênua? Gostaríamos de fazer um parênteses e observar que a atitude acrítica e ingênua dos educadores é o resultado da formação deficiente que recebem, por influência da legislação da Lei 5540, que expressa a ideologia da classe dominante. Dando continuidade ao que escrevíamos, concordamos com Saviani que é preciso buscar com coerência, lōgica e profundidade as tendências que as alternativas representam do ponto de vista histórico e da sociedade que as gerou.

Historicamente, o liberalismo do século XIX pensava a escola como um instrumento de participação democrātica. Na medida em que as mass as populares adquirissem conhecimentos, teriam condições de escolher seus dirigentes e assim se consolidaria a hegemonia burguesa e a democracia estaria implantada. Nessa fase a escola foi con siderada como "redentora da humanidade".

Mas os dados de realidade contrariaram essa expectativa,

1 SAVIANI, Derneval. Educação: do senso comum à consciência filosófica. São Paulo: Cortez Editora: Autores Associados, $1980-\mathrm{pg}$. 163. 
pois, as classes populares, alfabetizadas não votavam de acordo com os interesses da classe dominante. Nessa primeira fase, os liberais acreditavam que as escolas deveriam se multiplicar, lutaram para aumentar a quantidade de escolas, mas na segunda fase representada pela Escola Nova que se inaugurou, no Brasil em março de 1932 com o Manifesto dos Pioneiros em Educação, já no século xx a escola "redentora da humanidade" se "desacredita" e a classe dominante reagiu no sentido de que não bastava "a quantidade" de escolas, mas que era indispensāvel tratar da "qualidade" do ensino.

A Escola Nova propõe uma "revolução copērnica" no processo de ensino-aprendizagem: a educação centrada no aluno, nos seus interesses e necessidades; predominância do psicilógico sobre o lógico que resultou no "psicologismo". o adulto não é mais o modelo para a formação do educando, pois, se reconheceu que a criança não è um "adulto em miniatura". A metodologia como preocupação central: o alu no deveria "redescobrir" atravēs de experiências, os conhecimentos que compunham os currículos escolares. A questão dos fins da educação ficou relegada a um segundo plano.

Houve nessa segunda fase do liberalismo, um retrocesso. em relação à escola como "redentora da humanidade" que assumia o aspecto político da educação. A partir da "Escola Nova" foi atribuida às instituições escolares a autonomia em relação ao contexto sócio-político-social. Surge, então o segundo mito do liberalismo - a neutralidade da educação-centrada, agora nos métodos psicopedagógicos.

A segunda guerra mundial, enseja o aparecimento dos meios de comunicação de massa, como tentativas de atingir a população, em seu conjunto, superando as limitações da Escola Nova e o conservadorismo da escola tradicional.

Os meios de comunicação simplificam e deformam a cultura erudita, para-divulgá-la; a informātica, os computadores na educação, não se sustentam quando repetimos e perguntamos para que servem?

Num país como o Brasil com um sistema de ensino organizado 
para alijar a classe popular sócio-política e culturalmente. A quem serviriam as inovações propostas? Com um Estado que dá as costas à situação da classe popular e destina à educação verbas escassas, com a desvalorização do educador que se expressa nos salārios aviltados e na sua formação reconhecidamente deficiente, não faz sentido pensar em sofisticar o processo ensino-aprendizagem com a tecnologia da educação.

A questão substantiva da educação brasileira se concretiza, não na metodologia que é uma decorrência da filosofia de eđucação ado tada, mas na ideologia liberal que utiliza as instituições escolares para consolidar a estrutura de classes e a estrutura de poder das sociedades capitalistas.

Assim a defesa "da qualidade" de ensino expressa maior reacionarismo em relação à defesa da "quantidade" de escolas, porque esta medida amplia as oportunidades de aquisição de conhecimento para um nümero maior de alunos das classes populares.

A Escola Nova representa a degradação do ensino e essa afir mação foi percebida nos Estados Unidos, quando em 1975, a Rūssia lançou o primeiro Sputinik. Os princípios liberais da Escola Nova, bem como a metodologia da redescoberta dos conhecimentos, foram denunciados como responsáveis pela falta de consistência da aquisição do saber pelos alunos.

Quanto às outras alternativas apresentadas são pseudo-alter nativas do ponto de vista crítico que pretenda promover a classe popular.

Na perspectiva em que se encontra a política Educacional Bra sileira, Maria José Werebel, examina as inovações educacionais partindo do conceito de inovação. Para a referida autora inovar significa mudança para superar o que é tradicional ou inadequado.

Para que uma inovação se introduza no sistema educacional torna-se indispensāvel fazer o diagnóstico dos recursos humanos $e^{*}$ ma-

1 WEREBE, Maria Josē. In Inovação Educacional no Brasil: problemas e perspectivas. Coordenador Walter E. Garcia. S.Paulo. Cortez Editora: Autores Associados, 1980. 
teriais que mapearão a viabilidade da inovação proposta.

Torna-se fundamental ter clareza de que não hä autonomia da educação em relação ao contexto em que se insere; tex clareza de que um grau de ensino deve dar continuidade ao outro na verticalidade das séries no que se refere aos conhecimentos, que vão se tornando cada vez mais aprofundados e ter clareza ainda, de que dentro do sistema global da Educação deve haver um padrão de relações entre os objetivos propostos, obedecendo a sequência dos mais gerais para os mais específicos, objetivos esses priorizados pela Politica Educacional do Pais, dos Estados e dos Municípios.

Uma inovação educacional proposta precisa levar em conta que a insti tuição escolar é um ponto de convergência de conflitos:con flitos de classes sociais e de confronto das funções que uma instituição escolar pode exercer: a de reprodução da estrutura de classes e de poder da sociedade na qual se insere e a de mudança social.

Se essas condições não forem satisfeitas, as alternativas ou as inovações propostas se tornarão inócuas ou pseudo-alternativas, como quer Savianil, no sentido de que se alienam das condições da realidade concreta que as abrigam.

No Brasil, país periférico de economia capitalista dependente, com uma realidade educacional absolutamente deficiente e inadequada, onde somando os alunos reprovados, os repetentes e a evasão escolar, atinge a $60 \%$ da população, Saviani sugere como objetivos para uma Politica Educacional, vinculada a realidade brasileira, os que se seguem:

- educação para a sobrevivência, porque é preciso que a classe subalterna aprenda a tirar da situação adversa os meios de sobreviver; - educação para a libertação porque sabemos que o povo brasileiro his toricamente tem pouca experiência em relação ao exercício da democracia;

- educação para a comunicação porque para intervir e mudar uma situa-

1 SAVIANI, Demerval. Obra já citada. pg. 31. 
ção é necessārio ter consciência crítica da realidade, isto é, perceber o papel que desempenham e o lugar que ocupam na sociedade classista. Essa consciência poderā ser paulatinamente adquirida, através da comunicação e da troca de experiências entre os componentes das classes populares;

- educação para a transformação, pois, só uma mudança radical na estrutura de classes, permitirá que os objetivos acima referidos possam ser atingidos.

COMENTARIOS SOBRE O I ENCONTRO DE PROFISSIONAIS DE INFORMATTICA E RECURSOS HUMANOS

Queremos primeiro ressaltar e louvar a luta pelo reconhecimento do profissional da informática que se expressa na organização de um sindicato, como muito importante num país "onde o governo é mau patrão" (pg.23) e o trabalhador não é valorizado.

No entanto questionamos a utilização da informática, do computador nas Universidades e nas instituições escolares, de uma maneira geral.

Essa proposta nos parece descontextualizada, pois, num país subdesenvolvido, endividado e com uma população carente de noventa e sete milhões de individuos, não se justifica a tecnologia educacional, recurso altamente sofisticado. Ainda estamos precisando do "arroz e feijão" e perguntamos para qual faixa da população a informática traria benefícios?

Na página 22, Jorge Longano, assim se expressa... "A fonte que se desenha mais atrativa para uma categoria reconhecidamente mais educada, vamos dizer assim é o status. Na busca do status dificilmente se encontra a harmonia da união. Na busca do status as divergências pessọais, ideológico-políticas e uma sērie de outros fatores que acometem aqueles mais educados (o grifo é nosso), repito, tornam essa união bastante difícil"... 
Consideramos essa afirmação elitista expressando o desconhe cimento das razões históricas que estabeleceram essa dicotomia: categoria mais educada e categoria menos educada.

Alencar Rossi, na păgina 28, reconhece com muita clareza "que o conflito é permanente, que a contradição entre os interesses do trabalho e do capital são permanentes, mas que a busca de sua solução também deve ser permanente". Implicitamente está utilizando o princípio da dialética segundo o qual, a História caminha e se trans forma através do conflito e da contradição. Esses dois processos se constituem como motor da história.

No entanto, na página 29, parágrafo segundo, escreve "seria um absurdo imaginarmos que uma das duas partes, o capital ou 0 trabalho, pudesse existir procurando permanentemente destruir a outra parte". Consideramos essa afirmativa extremamente ingênua e acrí tica. Haverā alguma possibilidade, numa sociedade capitalista de se evitar a luta de classes?

Acrescenta "evitar que o conflito, embora existente, não venha a se transformas num confronto de proporções difíceis, onde a convivência venha a ser rompida."

Manter a convivência entre o patrão e o empregado, manter $\circ$ equilíbrio entre capital e trabalho, revela uma concepção de sociedade como uma totalidade sistêmica que se contrapõe à concepção de totalidade dialētica.

De acordo com Durmerval Trigueiro Mendes ${ }^{1}$ considerando sociedade como uma totalidade composta de partes que interagem dialë-: ticamente, possibilitamos o entendimento de que toda a ação, todo o pensamento e todas as situações sociais, mantêm relações entre si: relações determinadas por essa mesma totalidade que constituem e pela qual são constituidas. E importante assinalar que esta totalidade dialética se caracteriza por um saber radical, axiológico e transformador, de realidade se constituindo, buscando o sentido pelo qual as estruturas se organizam, preocupando-se com a "causalidade vertical",

1 MENDES, Durmerval Trigueiro (coordenador). Filosofia da Educação Brasileira. Rio de Janeiro: Civilização Brasileira, 1985. 
analisando e criticando a realidade e por isso mesmo, susceptível de transformā-la e que se opõe à totalidade sistêmica que se esgota na empiria como saber explicativo de sua funcionalidade, de realidade constituida, que se instala dentro da totalidade que ele procura recuperar contra eventuais desgarramentos das partes."

Na perspectiva da totalidade.. sistêmica está contido o princípio da conciliação entre empregado e patrão, "dentro da legalidade necessária para o jogo democrático." pg. 29.

Questionamos se a legislação se traduz em legitimidade: nem tudo que é legal, é legítimo e a jurisprudência tem na discriminação entre os referidos termos, o seu campo de ação.

Para finalizar esses comentärios, acrescentamos que a totalidade sistêmica neutraliza as reações das classes trabalhadoras, procurando acomodā-la e readaptá-la à empresa, por exemplo, no caso de uma greve, fazendo pequenas concessões, atendendo algumas reinvidicações. Com esse procedimento a empresa impede que os trabalhadores lutem por uma transformação radical e estāvel que lhes garanta os direitos que devem conquistar.

Therezinha Gonzaga Ferreira

Consultora Pedagógica do Centro Educacional Anísio Teixeira. 
BIBLIOGRAFIA

APPLE, Michael. Ideologia e Currículo. São Paulo: Brasiliense, 1982.

AZEVEDO, Fernando e Segnatārios. Reconstrução Educacional no Brasil. Manifesto dos pioneiros da educação nova. São Paulo: Nacional, 1932 .

BACCHETo, Sinēsio. Educação e Ideologia. Petrópolis: Vozes, 1967.

BERGER, Manfredo. Educação e Dependênciạ. Rio de Janeiro: Diffel, 1980 .

BOBBIO, Norbert. O conceito de sociedade civil. Rio de Janeiro: Graal, 1980.

BOURDIEU, Pierre e PASSERON, Jean Claude. A reprodução: elementos para uma teoria do sistema de ensino. Rio de Janeiro: Francisco Alves, 1975 .

BUFFA, Ester. Ideologia em conflito: escola püblica e escola privada. São Paulo: Cortez e Moraes Ltda., 1979.

CAPALBO, Creusa. Ideologia e Educação. São Paulo: Convívio, 1978.

CARDOSO, Fernando Henrique. Autoriarismo e democratização. Rio de Jạ neiro: Paz e Terra, 1975.

CHARLOT, Bernard. A Mistificação Pedagógica. Realidades Sociais Processos Ideológicos na Teoria da Educação. Săo Paulo: Zahar Editores, 1983.

CUNHA, Luiz Antonio R. Educação e desenvolvimento social no Brasil. Rio de Janeiro: Francisco Alves.

DEWEY, John. Democracia e educação. São Paulo: Nacional, 1959. DEWEY, John. Vida e educação. Rio de Janeiro: Melhoramentos, 1978. FREITAG, Bárbara. Escola, Estado e Sociedade. São Paulo: Edart, 1977. FREYRE, Paulo. Educação como prātica da liberdade. Rio de Janeiro: Paz e Terra, 1967.

FREYRE, Paulo. Pedagogia do oprimido. Rio de Janeiro: Paz e Terra, 1975.

GADOTTI, Moacir. Concepção dialética da educação. Um estudo introdutório. São Paulo: Autores Associados, 1983.

GADOTTI, Moacir. Educação e poder: introdução à pedagogia do conflito. São Paulo: Cortez e Moraes Ltda., 1980 .

GRAMSCI, Antonio. Concepção dialētica da histōria. Rio de Janeiro: Civilização Brasileira, 1966.

MENDES, Durmerval Trigueiro. Fenomenologia do processo educativo. Revista Brasileira de Estudos Pedagógicos, 1974, 134,140. 
MENDES, Durmerval Trigueiro. Indicação para uma política da educação no Brasil. Revista Brasileira de Estudos Pedagógicos, 1974, 136, 481 .

MENDES, Durmerval Trigueiro. Desenvolvimento, tecnocracia e universidade. Revista de Cultura vozes, $1975,6,5$.

MENDES, Durmerval Trigueiro. Notas para uma filosofia da educação Brasileira. Forum Educacional, 1977, 1, 903.

MENDES, Durmerval Trigueiro (coordenador). Filosofia da Educação Brasileira. Rio de Janeiro: Civilização Brasileira, 1985.

PEREIRA, Luiz. Capitalismo: notas teóricas. São Paulo: Duas Cidades, 1977.

PAOLI, N. Junqueira. Ideologia e hegemonia. As condições da produção da educação. São Paulo: cotty, 1981.

REIS FILHO, Casemiro. A educação e a ilusão liberal. São Paulo: Autores Associados, $19 \overline{81 .}$

RIBEIRO, Maria Luíza Santos. Histōria da Educação Brasileira. São Paulo: Cortez e Moraes, $197 \overline{9}$.

ROSSI, Wagner. Capitalismo e Educação. São Paulo: Cortez e Moraes Ltda., 1980.

SAVIANI, Dermeval. Educação: do senso comum à consciência filosófica. São Paulo: Cortez e Moraes Ltda., 1980.

SAVIANI, Dermeval. Escola e democracia ou a teoria da curvatura da vara. Revista da Associação Nacional de Educação, 1982, 1, 56 - 58 .

SAVIANI, Dermeval. Educação brasileira: Estrutura e sistema. São Pau 1o: Saraiva, 1981.

SNYDERS, Georges. Escola, classe e luta de classes. São Paulo:Cortez e Moraes, 1977.

SOUZA, Marilena Chauí de. Ideologia e Educação. Revista Educação e Sociedade, 1980,5 .

SouzA, Marilena Chauí de. O que é ideologia. São Paulo: Brasiliense, 1980 .

TEIXEIRA, Anísio. Valores proclamados e valores reais nas instituições escolares brasileiras, 1967, 86. Revista do INEP.

TEIXEIRA, Anísio. Educação não è previlēgio. Rio de Janeiro: José Olympio, 1957.

TEIXEIRA, Anísio. A escola e a estabilidade social. Revista Brasileira de Estudos Pedagógicos, $196 \overline{7}, 8 \overline{6}$.

VÅsQUEZ, Adolfo Sanchez. Filosofia da Praxis. Rio de Janeiro:Diffel, 1980 .

PINTO, Alvára Vieira. Consciência e realidade nacional. Rio de Janeiro: MEC/ISEB, 1960 .

WARDE, Miriam Jorge. Educação e estrutura social. A profissionalização em questão. São Paulo: Cortez e Moraes, 1979. 